\title{
Thermodysregulation in persons with spinal cord injury: case series on use of the autonomic standards
}

\author{
John P. Handrakis ${ }^{1,2} \cdot$ Michelle Trbovich $^{3} \cdot$ Ellen Merete Hagen $^{4} \cdot$ Michael Price $^{5}$
}

Received: 12 September 2017 / Revised: 11 October 2017 / Accepted: 12 October 2017

(c) International Spinal Cord Society 2017

\begin{abstract}
Introduction The ability to maintain core body temperature (Tcore) within a narrow range $\left(37 \pm 0.6{ }^{\circ} \mathrm{C}\right)$, despite exposure to a wide range of ambient temperatures, is essential in order to provide an optimal environment for vital organs, the central nervous system (CNS), and cellular processes to function. High-level (above T6) spinal cord injury (SCI) interrupts the autonomic nervous system's ability to carry out hypothalamic regulation of thermoregulatory mechanisms for both heat dissipation and conservation. This interruption leaves persons with high-level SCI vulnerable to hyper and hypothermia even during exposure to relatively mild ambient temperatures. The goal of the Autonomic Standards is to enable the clinician to quickly identify those individuals with SCI who may be most at risk for thermoregulatory dysfunction.

Case presentation Case 1: Heat Exhaustion, Case 2: Heat Stroke in absence of CNS symptoms, Case 3: Heat Exhaustion. Discussion The three cases demonstrate the signs and symptoms that may accompany hyperthermia in persons with SCI. The onset may be quite rapid and the condition persistent, despite ambient temperatures being much less intense than expected to be necessary to induce similar conditions in able-bodied (AB) persons. The responses of the persons in the case studies to the temperature regulation and autonomic control of sweating sections of the Autonomic Standards would identify them as being vulnerable and warrant providing appropriate exposure guidelines and precautions to them and their caregivers.
\end{abstract}

\section{Introduction}

Thermoregulation of core body temperature (Tcore) is the human body's most precisely-controlled homeostatic function [1]. Tcore is typically maintained within a narrow range $\left(37 \pm 0.6{ }^{\circ} \mathrm{C}\right)$, despite fairly wide fluctuations in ambient temperature in order to provide a favorable internal environment for optimal cellular processes [2-4]. In order to prevent Tcore from drifting outside this narrow range during environmental or internal temperature changes,

John P. Handrakis

john.handrakis@va.gov

1 VA RR\&D National Center for the Medical Consequences of Spinal Cord Injury, James J. Peters VA Medical Center, Bronx, NY, USA

2 New York Institute of Technology, Department of Physical Therapy, School of Health Professions, Old Westbury, NY, USA

3 UT Health Science Center at San Antonio, San Antonio, TX, USA

4 National Hospital for Neurology and Neurosurgery, Autonomic unit, London, UK

5 School of Life Sciences, Coventry University, Coventry, UK the hypothalamus orchestrates sympathetically-mediated responses of vasodilation and sweating to dissipate heat or vasoconstriction and shivering to retain heat and increase thermogenesis $[5,6]$. When thermoregulatory mechanisms are challenged by extreme hot or cold temperatures and are unable to adequately dissipate or retain heat, Tcore stability is compromised. This instability can cause hyperthermia (Tcore $\geq 38^{\circ} \mathrm{C}$ ) or hypothermia (Tcore $\leq 35^{\circ} \mathrm{C}$ ) [1] and if unchecked, can have morbid or mortal consequences. In the able-bodied $(\mathrm{AB})$ population, average rates of 658 heatrelated deaths and 1,301 cold-related deaths per year have been reported by the Centers for Disease Control (CDC) since 1999 [7, 8].

Neurological injury to any portion of the CNS that regulates Tcore, such as SCI, stroke, multiple sclerosis, etc. frequently results in thermoregulatory dysfunction and increases the risk of morbidity and mortality from exposure to extreme ambient temperatures. More specifically, SCI with an incidence of 17,000 cases per year and a prevalence of 282,000 persons in the U.S. [9], impairs autonomic, sensory, and motor pathways, significantly impacting mobility, internal organ function, and metabolic homeostasis. 
After SCI, central regulation of sympathetically-mediated heat dissipating and heat conserving mechanisms is interrupted [10-12]. Exposure to warmer ambient conditions in persons with SCI is met with impaired abilities to sweat and vasodilate, which allows even mildly hot ambient temperatures to cause Tcore to rise above normothermia [11, 13-15]. Conversely, during exposure to cooler ambient temperatures, impaired hypothalamic regulation of peripheral vasoconstriction causes peripheral heat loss to be greater in persons with tetraplegia than that in $\mathrm{AB}$ persons. The decline in Tcore and a delayed or absent shivering response [16], along with limited muscles available necessary for this latter response, can result in accidental hypothermia. Furthermore, conscious appreciation of thermal sensation is altered even in areas of skin with intact sensation, with a significantly narrower range of preferred local temperature (thermal comfort) when compared to AB controls [17]. The impaired ability to sense changes in ambient temperature combined with restricted mobility creates a vulnerability to hyperthermia and hypothermia, the risk of which is proportional to the level of injury (LOI), i.e., persons with tetraplegia are more at risk than those with paraplegia [14].

Finally, commonly prescribed medications in persons with SCI, i.e., sedatives and opioids may further reduce the impaired ability to conserve heat while anticholinergics, serotoninergics, and antihistamines can reduce heat dissipation [4]. In summary, decentralization of the autonomic nervous system, disrupted afferent input to the hypothalamus, and medications all synergistically compromise thermoregulatory function after SCI. While its effects can be life-threatening, incidence of heat or cold-related mortality in the SCI population is not currently available.

The American Spinal Injury Association (ASIA) and International Spinal Cord Society (ISCOS) established the International Standards to Document Remaining Autonomic Function after Spinal Cord Injury (ISAFSCI) [18]. The ISAFSCI documents thermoregulatory function in two areas, temperature regulations and autonomic control of sweating and can used as a quick tool for recognition and discussion of problems in these areas. The International Spinal Cord Injury Skin and Thermoregulation Function Basic Data Set advises collection of the person's thermoregulation history after SCI [19]. This series presents cases of individuals with SCI who presented to a physician or medical provider with signs and symptoms of thermodysregulation.

\section{Case presentation}

\section{Case report one}

A 39-year-old male with C6 level of injury [LOI, International Standards for Classification of Spinal Cord Injury
(ISNCSCI)], ASIA Impairment Scale (AIS) B (sensory incomplete) tetraplegia reported feeling hot after sitting outside in $37.8^{\circ} \mathrm{C}$ ambient outdoor temperature for thirty minutes before coming in for a research appointment. His previous research records noted an average baseline Tcore (oral) of $36.1^{\circ} \mathrm{C}$. However, upon arriving to the clinic, with an indoor ambient temp of $23.9^{\circ} \mathrm{C}$, his Tcore was $37.7^{\circ} \mathrm{C}$, which was $1.6^{\circ} \mathrm{C}$ higher than baseline. He complained only of fatigue but not dizziness, blurry vision, or pain. He reported feeling $7 / 8$ or "very hot" on the perceived thermal sensation scale [20].

Neurological exam revealed intact cranial nerve II-XII (CN II-XII) function and limb paralysis consistent with his known LOI and AIS score. Erythema of the skin was limited to the face, and he was anhidrotic. The skin above his LOI was warm to touch, while the skin below his LOI was cool. The remainder of the physical exam was benign. Medication was limited to mirabegron for treatment of neurogenic bladder.

While the indoor ambient temperature $\left(23.9^{\circ} \mathrm{C}\right)$ seemed to decrease his reported thermal discomfort, the subject selfcooled using a water sprayer (mister), which he carried at all times to assist in dissipating body heat and improve his thermal comfort as needed. Thirty minutes of rest at indoor room temperature while self-misting every 5-10 min, decreased the subject's Tcore only 0.2 to $37.5^{\circ} \mathrm{C}$. Despite this decrease, he still reported, feeling "uncomfortably hot". After an additional $30 \mathrm{~min}$ ( $1 \mathrm{~h}$ total) of rest indoors while misting, Tcore returned to $36.4{ }^{\circ} \mathrm{C}$ and thermal sensation to "comfortable".

The subject was later assessed by a clinician using the ISAFSCI form [18]. In the "Autonomic control of sweating" section, the subject reported hypohidrosis above and below his LOI. In the "Temperature regulations" section, he reported hyperthermia in the heat and hypothermia in the cold.

\section{Discussion}

This person experienced a rise in Tcore from a subnormal resting value of 36.1 to $37.7^{\circ} \mathrm{C}$, which is approaching hyperthermia $\left(>38.0^{\circ} \mathrm{C}\right)$ after $30 \mathrm{~min}$ of exposure to hot outdoor temperatures. His only complaint was fatigue and feeling "very hot." In persons with tetraplegia, frequencies of subnormal Tcore of up to $66 \%$ [21-23], and large increases in Tcore from 0.98 to $2.2^{\circ} \mathrm{C}$, during heat stress have been previously reported [14, 23]. Anhidrosis due to decentralization of the sympathetic nervous system is a common occurrence in persons with complete tetraplegia. However, vasodilation of the face and neck was intact, suggesting remaining sympathetic cholinergic function, whose neurological control mechanisms are not fully understood [24, 25]. 
This patient met criteria for heat exhaustion, which is defined as mild-moderate illness from exposure to high environmental heat with Tcore between $37-40{ }^{\circ} \mathrm{C}$ and symptoms including but not limited to weakness, discomfort, anxiety, and thirst [26].

Application of a water mister was the method of choice for this person to decrease his Tcore. However, Pritchett et al. [27] found that the application of artificial sweat was ineffective in attenuating heat strain during high-intensity arm exercise in persons with SCI. Of note, this study was limited to persons with paraplegia, whose Tcore does not rise as high as that of persons with tetraplegia secondary to more intact thermoregulatory mechanisms [14]. Finally, 60 min of rest were required for Tcore to return to baseline values, which reflects the inefficiency of this person's heat dissipation through vasodilation and sweating.

\section{Case report two}

A 32-year-old male with C7 LOI, AIS B tetraplegia, presented to the emergency department (ED) with a chief complaint of a "fever". He had been involved in an outdoor wheelchair games archery event for approximately $10 \mathrm{~h}$, at which time he began to feel hot and fatigued. The nurse on site at the sporting event reported an oral Tcore of $40.1^{\circ} \mathrm{C}$. He immediately received treatment with ice packs to the head and neck and was given cold water to drink. Upon arrival to the ED, his oral Tcore had decreased to $38.3^{\circ} \mathrm{C}$, and he subjectively reported less thermal discomfort. He complained of mild low back pain, but had no other symptoms of an infectious origin. His blood pressure was elevated to $154 / 78 \mathrm{~mm} \mathrm{Hg}$ with a heart rate of $73 \mathrm{bpm}$ in normal sinus rhythm. Respiratory rate and pulse oxygenation on room air were both within normal ranges. Physical examination revealed that the patient was not in acute distress.

Neurological examination revealed intact CN II-XII function and limb paralysis consistent with his LOI and AIS score. Integumentary inspection was notable for lack of sweating on all surfaces. The remainder of the physical exam was benign. Daily medications included midodrine, oxybutynin, baclofen, and gabapentin. Laboratory studies revealed a urinary white blood cell count (WBC) of $8 \times 10^{9} / \mathrm{L}$, mild serum leukocytosis at $11.4 \times 10^{9} / \mathrm{L}$, mildly elevated blood urea nitrogen (BUN) at $23 \mathrm{mg} / \mathrm{dl}$, and normal creatinine kinase (CK) at 191 U/L. The patient was diagnosed with heat exhaustion and treated with $1 \mathrm{~g}$ of acetaminophen, which resulted in complete resolution of symptoms two hours later with a temperature of $37.1^{\circ} \mathrm{C}$ at time of discharge.

At his annual evaluation a few months later, he was assessed by a clinician using the ISAFSCI form. In the "Autonomic control of sweating" section, he reported hypohidrosis above and below his LOI. In the "Temperature regulations" section, he reported hyperthermia in the heat and hypothermia in the cold.

\section{Discussion}

This person's Tcore $\left(40.1^{\circ} \mathrm{C}\right)$ was in the range of heat stroke $\left(>40^{\circ} \mathrm{C}\right)$, but he was diagnosed with heat exhaustion by the ED, secondary to lack of CNS sequela. His clinical presentation was significant for entire body anhidrosis and elevated blood pressure.

Heat stroke is defined as Tcore $>40{ }^{\circ} \mathrm{C}$ and the presence of CNS abnormalities such as impaired consciousness, delirium, blurry vision, nausea or dizziness, etc. and severe hyperthermia [26, 28]. While his Tcore rose above the threshold for heat stroke, his only clinical symptom was fatigue.

Significant laboratory findings consisted of elevated serum white blood cell count and BUN with normal CK. In $\mathrm{AB}$ persons exposed to continuous heat stress, skin vasodilation can approach maximal values to dissipate heat. To supplement this hemodynamic shift, a compensatory decrease in splanchnic blood flow (to maintain blood pressure) may lead to mesenteric ischemia followed by bacterial translocation triggering systemic inflammatory response syndrome (SIRS) [29]. While the mild elevation in WBCs and BUN could reflect a urinary tract infection (UTI), which is very common in this population, the lack of other UTI symptoms, such as increased urinary leaking, spasticity or persistent fever, suggests an alternative etiology which was not explored by the ED. While this patient did not develop SIRS, it should be considered that the abnormal lab values may reflect acute responses during heat stress.

The presence of blood pressure elevation in this case was unexpected, as typically heat stress results in hypotension. Two potential factors could explain the hypertension: autonomic dysreflexia (AD) and midodrine administration. Persons with SCI above T6 have an increased incidence of AD secondary to decentralized sympathetic vasomotor control of the splanchnic, lower extremity vasculature, and some or all of sympathetic cardiac control [30, 31]. AD is defined as a $>20 \mathrm{~mm} \mathrm{Hg}$ rise in SBP. Resting SBP was consistently in the area of $60 \mathrm{~mm} \mathrm{Hg}$, so $154 \mathrm{~mm} \mathrm{Hg}$ was clearly consistent with a diagnosis of AD. Heat stress is a profound sympatho-excitatory stimulus [29] and in persons with tetraplegia, AD may be triggered by heat stress [32], a hypertensive response that midodrine would exacerbate. In conclusion, although hypertension is not a classic symptom of heat stress and heat stress is not a typical cause of AD, it is a sympathomimetic stress. Therefore, both AD and midodrine could be implicated as contributors to the unexpected blood pressure elevation in this case. 
The cooling methods of ice packs over head and neck and cold water provided subjective comfort and an acute decrease in Tcore $\left(40.1\right.$ to $\left.38.3^{\circ} \mathrm{C}\right)$. Ice slurries, or ice crystals suspended at moderate to high volume fractions in sucrose solution, have been shown to improve heat storage capacity in $\mathrm{AB}$ persons $[33,34]$. The application of ice to the head and neck should be an effective method of cooling as these areas contain a high concentration of thermoreceptors [35, 36]. Although there is evidence that neck cooling improves performance in hot conditions in $\mathrm{AB}$ persons, it does not significantly affect Tcore [37]. Alternatively, in the SCI population, ice vests, cooling hats, and neckbands have been shown to reduce Tcore during heat stress, so this intervention may explain the significant decrease in Tcore while en route to the ED [38].

\section{Case report three}

A 38-year-old male with chronic C6 AIS A (motor and sensory complete), reported to his clinician that he thought the anhidrosis he had since injury was contributing to his "not feeling well" when participating in sports and while in hot environments. To measure Tcore response objectively, the patient's physiological responses to heat were assessed by use of a heating blanket.

The patient's Tcore (tympanic measurement) rose from 36.1 to $36.9{ }^{\circ} \mathrm{C}$ after $40 \mathrm{~min}$ of heating, but continued to rise even after the blanket was removed, which led to cooling treatment with ice packs to the forehead and abdomen. Tcore continued to rise to a maximum of $37.4{ }^{\circ} \mathrm{C}$, during the following $37 \mathrm{~min}$ after removal of the heating blanket, despite continuous cooling treatment.

Visual integumentary inspection revealed that sweating was minimal and limited to the patient's forehead during heating. Mean brachial systolic blood pressure (SBP) was $76.6 \mathrm{~mm} \mathrm{Hg}$ pre-heating, $59.5 \mathrm{~mm} \mathrm{Hg}$ during heating, and decreased further to $50.5 \mathrm{~mm} \mathrm{Hg}$ post-heating.

The patient complained of symptoms of nausea, dizziness, and chest tightness during the heating period and developed lower extremity spasms towards the end of the heating period. These symptoms continued for $30 \mathrm{~min}$ postheating.

While the ISAFSCI form was not completed by his clinician in this event, the history and Tcore responses during heating suggest that he would have reported hypohidrosis below his LOI and hyperthermia in the heat.

\section{Discussion}

This person with tetraplegia complained that he did not feel well during sports participation and in the heat. As in case one, his resting Tcore was subnormal at $36.1{ }^{\circ} \mathrm{C}$ and rose $1.3{ }^{\circ} \mathrm{C}$ to normothermia at $37.4{ }^{\circ} \mathrm{C}$. Furthermore, not only did his Tcore rise $0.8^{\circ} \mathrm{C}$ during $40 \mathrm{~min}$ of heat application, but continued to rise an additional $0.5^{\circ} \mathrm{C} 37 \mathrm{~min}$ post heating, despite application of ice-packs. As in the previous cases, anhidrosis impaired efficient heat dissipation. While he complained of nausea, dizziness, and chest tightness soon after initiation of the heat challenge, these symptoms may have been due the $17 \mathrm{~mm} \mathrm{Hg}$ decrease in SBP secondary to reflex vasodilation, not solely of heat exhaustion. Assessment using the ISAFSCI form would have identified this person as vulnerable to hyper and hypothermia as well as hypotension.

\section{Discussion}

Thermoregulatory dysfunction is a well-known consequence of SCI and has been shown to negatively impact comfort and the ability to perform vital activities during the cooler seasons in persons with tetraplegia [39]. Recent findings from our survey study (unpublished) have shown that warmer seasonal temperatures may present a similar barrier in persons with tetraplegia to engage in activities outside of their homes as well as cause increased physical discomfort in persons with both paraplegia and tetraplegia [40]. Taking the trend toward increasing global temperatures into account, it is important to address the impact of an increase of $1.5^{\circ} \mathrm{C}$ in global temperature on health [41]. Considering the lower socio-economic status of many persons living with SCI, some may not be able to afford air conditioning or heating units to provide a therrnoneutral environment. This lack of protection against climate change is especially true for those persons with SCI living in underdeveloped countries. Thus, increases in global temperature may further challenge decentralized thermoregulatory mechanisms and expose the vulnerability of persons with SCI to hyperthermia and challenge survival when attempting to cope with prolonged heat exposure [42-46].

Outdoor exercise is more easily accessible than a temperature-controlled gym for most persons with SCI. During conditions of high ambient temperatures, impaired thermoregulation limits exercise tolerance and may pose a significant threat to life due to hyperthermia. A similar thermal strain is created endogenously by metabolically active muscles during exercise, even in thermoneutral environments. This exercise-induced discomfort of thermal strain can be a deterrent for persons with SCI to exercise, either indoors or outdoors. Since individuals with SCI have an increased prevalence of cardiovascular disease, diabetes, and obesity compared to the $\mathrm{AB}$ population, regular exercise is commonly prescribed for prevention and amelioration of these comorbidities [47-49].

Given its potential to negatively impact quality of life (QoL), participation in exercise, and safety during outdoor 
activities, the ability to quantify thermoregulatory dysfunction is essential for the treating clinician to more accurately predict who is most impacted by this sequela of SCI.

\section{Topics of comparison}

\section{Presenting signs/symptoms}

The main presenting symptoms in all cases were fatigue, "not feeling well," or feeling "very hot". The common physical exam finding in all cases was anhidrosis, which is a sign of heat stroke, but should not be confused with sympathetic nervous system decentralization from SCI. Finally, the definition of heat stroke is Tcore $>40{ }^{\circ} \mathrm{C}$ with associated CNS abnormalities. Despite a Tcore $>40^{\circ} \mathrm{C}$, case two did not have any associated CNS sequela, so was diagnosed with heat exhaustion. His symptoms were identical to cases one and three despite his Tcore being $2{ }^{\circ} \mathrm{C}$ higher than both cases.

CNS abnormalities from heat stroke typically result from reduced cerebral blood flow (CBF) that is a consequence of SIRS. The absence of CNS abnormalities in case two suggests no compromise of $\mathrm{CBF}$, which leads us to question whether persons with tetraplegia are less likely to experience CNS symptoms than $\mathrm{AB}$ persons for a given heat load. Persons with tetraplegia have lower resting SBP than $A B$ persons [50]. As such, we hypothesize that the lack of CNS changes in this person may have been due to: (1) the change in CBF was less drastic as persons with tetraplegia may have accommodated to lower CBF values [50]; or (2) decentralization of the sympathetic nervous system may have impaired both the expected compensatory vasoconstriction of the mesenteric arteries and increases in skin blood flow during heat stress [29]. Further investigations are needed to examine this hypothesis.

\section{Prolonged latency to normothermia post heat stress}

Time for Tcore to return to baseline after heat stress in $A B$ persons is typically less than $30 \mathrm{~min}$. In all three cases the time to return to baseline was prolonged, ranging from 1-2 $\mathrm{h}$, which increases heat-related cytotoxicity and SIRS risk that underlie the pathophysiology of heat stress.

\section{Cases with hypothermia}

Although we only contacted a limited number of clinicians, we did not receive any cases of hypothermia in persons with SCI. We are not sure if this was because the clinicians' locale was seasonally warmer or because hypothermia may have a more insidious onset and not produce the same discomfort as hyperthermia. We speculate that the frequency of hypothermia in persons with SCI may be under-reported.

\section{Autonomic standards recommendations}

The current ISAFSCI Form has two sections that attempt to subjectively define remaining thermoregulatory function after SCI: temperature regulations (history of hyper or hypothermia) and autonomic control of sweating (reported hyperhidrosis above the LOI and hyper or hypohidrosis below the LOI). The goals are that this assessment could: (1) be conducted internationally as part of a simple bedside assessment, and (2) help clinicians quantify the severity of thermoregulatory dysfunction and, thus identify persons most at risk so that they can be counseled accordingly. Currently, its validity is dependent on the patient's accuracy as a historian rather than objective data, and it does not quantify the extent or severity of dysfunction.

The Thermoregulation sub-committee of the Autonomic standards has proposed improving the objectivity of both sections. The revised temperature regulation assessment would include measurement of resting Tcore after fifteen minutes of rest, with method of assessment, i.e., oral, rectal, or tympanic, with time of day, and ambient room temperature recorded. Ranges for Tcore would be provided for uniform classification of patients as hyperthermic, normothermic, or hypothermic. Secondly, the ambient temperature at which persons with SCI find themselves most comfortable would be documented. Finally, the autonomic control of sweating section would identify the lowest dermatomal level where sweating occurs.

These recommendations represent the continuing evolution of the autonomic standards in creating a more objective and comprehensive autonomic assessment to identify persons at risk of thermoregulatory dysfunction. Everyday practitioners would benefit from this increased objectivity by identifying patients most at risk for thermoregulatory related illnesses, and most appropriate for education of risk factors, safety, and available interventions for the patient, caregivers, and healthcare providers.

\section{Treatment recommendations}

Despite showing promise in $\mathrm{AB}$ persons, there is limited evidence for the efficacy of whole body cooling, cooling vests, and hand/foot cooling in persons with SCI [38]. Cooling vests reveal conflicting results in persons with SCI due to varied study environments, exercise activities and heterogeneous LOI and AIS of persons with SCI studied. In persons with paraplegia with varied AIS grades, the application of artificial sweat in the form of a spray bottle to the skin of the head, neck, and forearms was not effective at reducing Tcore [27]. However, persons with paraplegia are 
able to achieve similar sweat rates to $\mathrm{AB}$ persons despite a reduced surface area of sweating and, therefore, achieve similar rates of evaporative cooling [51-53]. Artificial sweat may be more efficacious in persons with complete (AIS A) tetraplegia who generally do not have sweating capacity. The combined intervention of precooling (using a cooling vest) and artificial sweat (using water from a spray bottle) during exercise was recently studied in athletes with tetraplegia and was found to be effective in reducing Tcore [54].

The most recent systematic review article on cooling techniques in persons with SCI concluded that [1] cooling vests currently have the best evidence of reducing subjective heat strain and improving performance and [2] precooling with cooling during activities should be more extensively studied [38]. It should be considered that studies of cooling techniques in persons with SCI have reported decreased thermal strain and decreased skin temperature, but Tcore either increased or remained unchanged [55, 56]. Such an attenuated perception of thermal strain can increase the risk of heat injury in this population. Since cooling vests have not been shown to consistently reduce Tcore in this population, patients must be cautioned that while they may feel cooler using a vest, their risk of heat-related illness may be unchanged.

One of the difficulties in providing effective treatment of thermoregulatory dysfunction is the lack of complete understanding of the neurological control of vasomotor and sudomotor mechanisms in persons with and without SCI [57, 58]. Krassioukov et al. [58] stated, "mechanisms of temperature dysregulation need further studies, as differentiating between those with and without temperature dysregulation may be helpful in discerning those with autonomic completeness especially in the setting of motor and sensory completeness".

\section{Patient education}

Given the potential for heat-related illness in the setting of high ambient heat or exercise, persons with high-level (> T6) SCI, especially those with complete cervical injuries should be educated about risks.

We advise avoiding continuous exposure to ambient temperatures $>35^{\circ} \mathrm{C}$ for greater than $4 \mathrm{~h}$, hydrating continuously and applying cold compresses or water spray to the face every 15-20 min while in the heat. Persons identified to be at risk should also designate an accessible cool environment prior to heat exposure/intense exercise. Should symptoms of dizziness, fatigue, nausea, altered mental status, or other symptoms of heat exhaustion/stroke arise, they should immediately transfer to the cool environment and seek medical attention.

We have not provided case studies of persons with SCI presenting with hypothermia in this series. However, persons with high-level SCI who are identified by the ISAFSCI as having impaired "Autonomic control of sweating" and "Temperature regulations" are also at risk for hypothermia. Durations of exposure $>2 \mathrm{~h}$ to ambient temperatures $<18^{\circ} \mathrm{C}$, conditions of low sunlight, high humidity, and high wind speed all accelerate the rate of heat loss and further increase that risk. General advice, such as minimizing duration of exposure to the aforementioned ambient conditions, layering clothing, insulating the core, and staying dry, is prudent. If common symptoms of hypothermia arise, e.g., shivering, clumsiness, confusion, or sleepiness [59], the person should transfer to a warm environment and seek medical attention.

Such education can hopefully minimize the associated morbidity, mortality, and negative effects of thermodysregulation on QoL.

Acknowledgements We would like to acknowledge Ms. Nina S. Kumar, B.S. for her efforts in the assembly of this case study series. This project was supported, in part, by the Department of Veterans Affairs, Veterans Health Administration, Rehabilitation Research \& Development Service Center for the Medical Consequences of Spinal Cord Injury (Grant \#B9212-C, \#B2020-C).

Disclosure We certify that no party having a direct interest in the results of the research supporting this article has or will confer a benefit on us or on any organization with which we are associated AND, if applicable, we certify that all financial and material support for this research (e.g., NIH or NHS grants) and work are clearly identified in the title page of the manuscript.

\section{Compliance with ethical standards}

Conflict of interest The authors declare that they have no competing interests.

\section{References}

1. Sessler DI. Thermoregulatory defense mechanisms. Crit Care Med. 2009;37:S203-10.

2. Guyton AHJ. Textbook of medical physiology. 11th ed. Elsevier Science; Philadelphia, PA, 2006.

3. Castellani JW, Young AJ, Ducharme MB, Giesbrecht GG, Glickman E, Sallis RE, et al. American College of Sports Medicine position stand: prevention of cold injuries during exercise. Med Sci Sports Exerc. 2006;38:2012-29.

4. Cheshire WP Jr. Thermoregulatory disorders and illness related to heat and cold stress. Auton Neurosci. 2016;196:91-104

5. Fealey RD. Interoception and autonomic nervous system reflexes thermoregulation. Handb Clin Neurol. 2013;117:79-88.

6. Morrison SF, Nakamura K. Central neural pathways for thermoregulation. Front Biosci (Landmark Ed). 2011;16:74-104.

7. Heat-Related Deaths After an Extreme Heat Event - Four States, 2012, and United States, 1999-2009. In: Prevention CfDCa, editor. Atlanta, GA: Centers for Disease Control and Prevention 2013. p. 433-6.

8. Xu J. QuickStats: Number of Hypothermia-Related Deaths,* by Sex-National Vital Statistics System, United States, $\dagger$ 1999-2011§. Washington, DC: Centers for Disease Control and Prevention 2013 Contract No.: 51. 
9. National Spinal Cord Injury Statistical Center, Facts and Figures at a Glance. Birmingham, AL: University of Alabama at Birmingham, 2016.

10. Downey JA, Chiodi HP, Darling RC. Central temperature regulation in the spinal man. J Appl Physiol. 1967;22:91-4.

11. Guttmann L, Silver J, Wyndham CH. Thermoregulation in spinal man. J Physiol. 1958;142:406-19.

12. Randall WC, Wurster RD, Lewin RJ. Responses of patients with high spinal transection to high ambient temperatures. J Appl Physiol. 1966;21:985-93.

13. Silver JR, Randall WC, Guttmann L. Spinal mediation of thermally induced sweating. J Neurol Neurosurg Psychiatr. 1991;54:297-304.

14. Price MJ, Campbell IG. Effects of spinal cord lesion level upon thermoregulation during exercise in the heat. Med Sci Sports Exerc. 2003;35:1100-7.

15. Nicotra A, Asahina M, Mathias CJ. Skin vasodilator response to local heating in human chronic spinal cord injury. Eur J Neurol. 2004;11:835-7.

16. Downey JA, Darling RC, Chiodi HP. The response of tetraplegia patients to cold. Arch Phys Med Rehabil. 1967;48:645-9.

17. Attia M, Engel P. Thermoregulatory set point in patients with spinal cord injuries (spinal man). Paraplegia. 1983;21:233-48.

18. Krassioukov A, Biering-Sorensen F, Donovan W, Kennelly M, Kirshblum S, Krogh K, et al. International standards to document remaining autonomic function after spinal cord injury. J Spinal Cord Med. 2012;35:201-10.

19. Karlsson AK, Krassioukov A, Alexander MS, Donovan W, Biering-Sørensen F. International spinal cord injury skin and thermoregulation function basic data set. Spinal Cord. 2012;50:512-6.

20. Young AJ, Sawka MN, Epstein Y, Decristofano B, Pandolf KB. Cooling different body surfaces during upper and lower body exercise. J Appl Physiol. (1985). 1987;63:1218-23.

21. Khan S, Plummer M, Martinez-Arizala A, Banovac K. Hypothermia in patients with chronic spinal cord injury. J Spinal Cord Med. 2007;30:27-30.

22. Mollinger LA, Spurr GB, el Ghatit AZ, Barboriak JJ, Rooney CB, Davidoff DD, et al. Daily energy expenditure and basal metabolic rates of patients with spinal cord injury. Arch Phys Med Rehabil. 1985;66:420-6.

23. Trbovich MB, Kiratli JB, Price MJ. The effects of a heat acclimation protocol in persons with spinal cord injury. J Therm Biol. 2016;62:56-62.

24. Normell LA. Distribution of impaired cutaneous vasomotor and sudomotor function in paraplegic man. Scand J Clin Lab Invest Suppl. 1974;138:25-41.

25. Johnson JM, Kellogg DL Jr. Thermoregulatory and thermal control in the human cutaneous circulation. Front Biosci (Schol Ed). 2010;2:825-53.

26. Bouchama A, Knochel JP. Heat stroke. N Engl J Med. 2002;346:1978-88.

27. Pritchett RC, Bishop PA, Yang Z, Pritchett KL, Green JM, Katica $\mathrm{CP}$, et al. Evaluation of artificial sweat in athletes with spinal cord injuries. Eur J Appl Physiol. 2010;109:125-31.

28. Winkenwerder M, M NS. Disorders due to heat and cold. In: Goldman L, Ausiello D, editors. Cecil medicine. Philadelphia: Elsevier Science; 2007. p. 763-7.

29. Leon LR, Helwig BG. Heat stroke: role of the systemic inflammatory response. J Appl Physiol. (1985). 2010;109:1980-8.

30. Krassioukov A, Claydon VE. The clinical problems in cardiovascular control following spinal cord injury: an overview. Prog Brain Res. 2006;152:223-9.

31. Teasell RW, Arnold JM, Krassioukov A, Delaney GA. Cardiovascular consequences of loss of supraspinal control of the sympathetic nervous system after spinal cord injury. Arch Phys Med Rehabil. 2000;81:506-16.

32. Ziegler MG, Ruiz-Ramon P, Shapiro MH. Abnormal stress responses in patients with diseases affecting the sympathetic nervous system. Psychosom Med. 1993;55:339-46.

33. Siegel R, Mate J, Brearley MB, Watson G, Nosaka K, Laursen PB. Ice slurry ingestion increases core temperature capacity and running time in the heat. Med Sci Sports Exerc. 2010;42:717-25.

34. Gilbert AJ, Oppong FK, Farr RS. Flow and evolution of icesucrose crystal mushes. Phys Rev E. 2017;95:042606.

35. Cotter JD, Taylor NA. The distribution of cutaneous sudomotor and alliesthesial thermosensitivity in mildly heat-stressed humans: an open-loop approach. J Physiol. 2005;565:335-45.

36. Nakamura M, Yoda T, Crawshaw LI, Yasuhara S, Saito Y, Kasuga M, et al. Regional differences in temperature sensation and thermal comfort in humans. J Appl Physiol. (1985). 2008;105:1897-906.

37. Tyler CJ, Sunderland C. Neck cooling and running performance in the heat: single versus repeated application. Med Sci Sports Exerc. 2011;43:2388-95.

38. Griggs KE, Price MJ, Goosey-Tolfrey VL. Cooling athletes with a spinal cord injury. Sports Med. 2015;45:9-21.

39. Handrakis JP, Rosado-Rivera D, Singh K, Swonger K, Azarelo F, Lombard AT, et al. Self-reported effects of cold temperature exposure in persons with tetraplegia. J Spinal Cord Med. 2017;40:389-95.

40. Tittley TD, Tascione OF, Bart J, Barton C, Cirnigliaro CM, Spungen AM, et al. Seasonal heat exposure in persons with spinal cord injury: Self-reported effects. Albuquerque, New Mexico: American Spinal Injury Association 2017 Annual Scientific Meeting; 2017.

41. Flouris AD, Kenny GP. Heat remains unaccounted for in thermal physiology and climate change research. F1000Research. 2017;6:221.

42. Hanna EG, Tait PW. Limitations to thermoregulation and acclimatization challenge human adaptation to global warming. Int $\mathrm{J}$ Environ Res Public Health. 2015;12:8034-74.

43. Hossain MS, Rahman MA, Bowden JL, Quadir MM, Herbert RD, Harvey LA. Psychological and socioeconomic status, complications and quality of life in people with spinal cord injuries after discharge from hospital in Bangladesh: a cohort study. Spinal Cord. 2016;54:483-9.

44. Oderud T. Surviving spinal cord injury in low income countries. Afr J Disabil. 2014;3:80.

45. Krause JS, Dismuke CE, Acuna J, Sligh-Conway C, Walker E, Washington $\mathrm{K}$, et al. Race-ethnicity and poverty after spinal cord injury. Spinal Cord. 2014;52:133-8.

46. Weerts E, Wyndaele JJ. Accessibility to spinal cord injury care worldwide: the need for poverty reduction. Spinal Cord. 2011;49:767.

47. Cragg JJ, Noonan VK, Dvorak M, Krassioukov A, Mancini GB, Borisoff JF. Spinal cord injury and type 2 diabetes: results from a population health survey. Neurology. 2013;81:1864-8.

48. Cragg JJ, Noonan VK, Krassioukov A, Borisoff J. Cardiovascular disease and spinal cord injury: results from a national population health survey. Neurology. 2013;81:723-8.

49. Bauman WA, Spungen AM. Carbohydrate and lipid metabolism in chronic spinal cord injury. J Spinal Cord Med. 2001;24: 266-77.

50. Handrakis JP, DeMeersman RE, Rosado-Rivera D, LaFountaine MF, Spungen AM, Bauman WA, et al. Effect of hypotensive challenge on systemic hemodynamics and cerebral blood flow in persons with tetraplegia. Clin Auton Res. 2009;19:39-45.

51. Price MJ, Campbell IG. Thermoregulatory responses of paraplegic and able-bodied athletes at rest and during prolonged upper body 
exercise and passive recovery. Eur J Appl Physiol Occup Physiol. 1997;76:552-60.

52. Price MJ, Campbell IG. Thermoregulatory responses of spinal cord injured and able-bodied athletes to prolonged upper body exercise and recovery. Spinal Cord. 1999;37:772-9.

53. Dawson B, Bridle J, Lockwood RJ. Thermoregulation of paraplegic and able bodied men during prolonged exercise in hot and cool climates. Paraplegia. 1994;32:860-70.

54. Griggs KE, Havenith G, Paulson TAW, M JP, Goosey-Tolfrey VL. Effects of cooling before and during simulated match play on thermoregulatory responses of athletes with tetraplegia. J Sci Med Sport. 2017;20:819-24.

55. Bongers CC, Eijsvogels TM, van Nes IJ, Hopman MT, Thijssen DH. Effects of cooling during exercise on thermoregulatory responses of men with paraplegia. Phys Ther. 2016;96:650-8.
56. Goosey-Tolfrey VL, Diaper NJ, Crosland J, Tolfrey K. Fluid intake during wheelchair exercise in the heat: effects of localized cooling garments. Int J Sports Physiol Perform. 2008;3:145-56.

57. Charkoudian N. Mechanisms and modifiers of reflex induced cutaneous vasodilation and vasoconstriction in humans. J Appl Physiol. (1985). 2010;109:1221-8.

58. Krassioukov AV, Karlsson AK, Wecht JM, Wuermser LA, Mathias CJ, Marino RJ, et al. Assessment of autonomic dysfunction following spinal cord injury: rationale for additions to International Standards for Neurological Assessment. J Rehabil Res Dev. 2007;44:103-12.

59. Hypothermia and older adults. Bethesda, Maryland: National Institutes of Health; 2016. Available from: https://www.nih.gov/ news-events/news-releases/hypothermia-older-adults- 0 . 